\title{
Análise econômica de esquemas alternativos de controle leiteiro
}

[Economic analysis of alternative schemes of milk recording]

V.L. Cardoso ${ }^{1}$, L.D. Cassoli ${ }^{2}$, M.M. Guilhermino ${ }^{3}$, P.F. Machado ${ }^{2}$, J.R. Nogueira ${ }^{1}$, M.A.R. Freitas ${ }^{4}$

${ }^{1}$ Instituto de Zootecnia, APTA/SAA-SP

Avenida Bandeirantes, 2419

14030-670 - Ribeirão Preto, SP

${ }^{2}$ Departamento de Zootecnia, ESALQ-USP

${ }^{3}$ Universidade Federal do Rio Grande do Norte

${ }^{4}$ Departamento de Genética, FMRP - USP

\begin{abstract}
RESUMO
Compararam-se os custos de seis esquemas de controle leiteiro (CL), estabelecidos com base em diferentes freqüências de controles (com possibilidade de controle trimestral supervisionado e aproveitamento do $\mathrm{CL}$ da fazenda), no número de ordenhas e na realização de análises qualitativas (composição do leite e/ou contagem de células somáticas). Computaram-se os percentuais que os custos totais do $C L$ representariam na receita bruta mensal do leite $(C L / R B)$ e na receita líquida mensal $(\mathrm{CL} / \mathrm{RL}$ ). $\mathrm{O}$ esquema tradicional (freqüência mensal) apresentou o mais elevado custo mensal e os maiores $\mathrm{CL} / \mathrm{RB}$ e $\mathrm{CL} / \mathrm{RL}$. Esquemas com intervalo maior entre controles e amostragem em ordenhas alternadas resultaram na redução dos custos com diárias e quilometragem. O custo mensal do CL variou de $0,68 \%$ a $1,8 \%$ sobre a receita bruta do leite e de $6,6 \%$ a $17,0 \%$ sobre a receita líquida.
\end{abstract}

Palavras-chave: bovino leiteiro, controle leiteiro, análise econômica

\begin{abstract}
Costs of six different milk recording schemes based on the interval between controls (with the possibility of a three-month interval supervision control and the use of the farmers' milk recording data), the number of milking recorded and milk quality analyses (milk composition and/or somatic cell counting) were compared. The ratio milk recording costs over gross income $(C L / R B)$ and over net income $(C L / R L)$ were also estimated. The traditional scheme (monthly recording) presented the highest monthly costs and ratios $C L / R B$ and $C L / R L$. Schemes with longer intervals between controls and alternate sampling presented the lowest costs due to the reduction of travel costs. Monthly milk recording costs over milk gross income and over net income ranged from $0.68 \%$ to $1.8 \%$ and from $6.6 \%$ to $17.0 \%$, respectively.
\end{abstract}

Keywords: dairy cattle, milk recording, economic analysis

\section{INTRODUÇÃO}

O controle leiteiro (CL) constitui um instrumento de tomada de decisão que visa ao aumento da eficiência econômica dos rebanhos leiteiros. Ele serve para orientar o manejo alimentar, auxiliar o controle e prevenção de mastite, para apontar diretrizes de descarte e de melhoramento genético e para a promoção comercial do rebanho.

Conforme relatório do International Committee on Animal Recording (ICAR), órgão internacional que sistematiza as informações

Apoio financeiro FAPESP

Recebido para publicação em 13 de novembro de 2001

Recebido para publicação, após modificações, em 3 de abril de 2004

E-mail: vlcardoso@aptaregional.sp.gov.br 
sobre animais para se proceder a avaliação genética de animais usados simultaneamente em vários países, existe a possibilidade de se usar diversas alternativas de controle leiteiro (Wilmink, 1998). Segundo esse autor, o ICAR aceita dois critérios de controle leiteiro, o oficial e o feito pelo próprio produtor. Além disso, o controle pode ser feito com intervalos que variam de três a seis semanas, podendo ser considerada apenas uma amostra da produção por dia (no caso de mais de uma ordenha). Cada país, entretanto, define seu regulamento. No Brasil o controle leiteiro é conduzido por controlador oficial, em geral feito mensalmente, com intervalo máximo de 45 dias entre controles, e realizado de modo a coletar amostras do total de leite produzido em 24 horas. Exemplos extremos são a Nova Zelândia, onde o número de controles por lactação é escolhido pelo fazendeiro e os Estados Unidos, onde todas as lactações são usadas em avaliações genéticas, independente do número de registros com os quais ela foi estimada, mesmo que seja com base em um único registro, controlado tanto pelo produtor quanto pelo técnico. Hoje o que se observa é uma tendência de os métodos de controle leiteiro se tornarem mais flexíveis quanto à freqüência e ao critério adotado (Wilmink, 1998).

No Brasil houve, nos últimos anos, redução no número de rebanhos controlados. Segundo os produtores, esse fato é atribuído ao alto custo de realização do controle leiteiro oficial. Segundo dados da Associação Brasileira de Criadores de Bovinos da Raça Holandesa em 2000 havia 96.649 animais inscritos no Serviço de Controle Leiteiro (SCL) e 66.014 lactações foram encerradas naquele ano. Dos 790 criadores inscritos, $89 \%$ eram de São Paulo, Paraná e Minas Gerais, e do total de lactações encerradas, $29 \%$ eram provenientes do Estado de São Paulo (19.146 lactações). Entre 1998 e 2000 foi observada queda de $18 \%$ e $7,5 \%$, respectivamente, no número de criadores e no de animais inscritos no SCL. No Estado de São Paulo, o efetivo bovino considerado como sendo de leite é de 1.708.155 cabeças (Anuário..., 1999/2000). A porcentagem de animais em controle leiteiro é muito pequena. Mesmo considerando todas as raças, fez-se o controle leiteiro de no máximo 5.000 vacas por ano. Historicamente, considera-se que as raças especializadas são responsáveis por $20 \%$ da produção de leite na região Sudeste do Brasil, e $80 \%$ é proveniente de rebanhos mestiços. Os números indicam que grande percentual do total de leite produzido provem de rebanhos não controlados.

Para o controle leiteiro qualitativo obtêm-se amostras de leite para análises de composição e contagem de células somáticas (CCS). Essas análises têm um custo e o retorno destes gastos está diretamente relacionado ao pagamento diferenciado do leite pela qualidade. Madalena (2000b) calculou os valores econômicos para produção de leite, gordura e proteína levando em consideração o sistema de pagamento de duas importantes empresas de laticínios do Paraná e de Minas Gerais. Para o sistema de pagamento do Paraná, que contempla a qualidade do leite e os teores de gordura e proteína, o valor econômico dos três componentes foram positivos, sendo similares para gordura e proteína e ambos mais altos do que o valor calculado para o veículo. No sistema de pagamento de Minas Gerais, somente o valor do veículo foi positivo. Em outro estudo, Madalena (2000a) demonstrou que a aquisição de sêmen importado com base no seu valor genético para gordura e proteína poderia trazer lucro para a situação do Paraná, enquanto que o uso de sêmen de reprodutores superiores para essas características em Minas Gerais resultaria em prejuízo. Por constituir um indicativo da ocorrência de mastite sub-clínica e por influenciar aspectos de duração e qualidade do leite e de produtos derivados (Dürr e Rorato, 2000), a CCS também costuma ser levada em consideração para fins de composição do preço do leite por alguns laticínios, seja premiando os rebanhos de baixa CCS, seja penalizando os de alta CCS. O objetivo deste trabalho foi realizar uma avaliação econômica de esquemas alternativos de controle leiteiro, tendo como base a situação do Estado de São Paulo.

\section{MATERIAL E MÉTODOS}

Foram realizadas comparações quanto à freqüência de controles (mensal, bimensal e supervisão trimestral com aproveitamento dos controles realizados pelo produtor) e quanto ao esquema de ordenhas (controle de uma ou mais ordenhas, manhã ou tarde, alternadamente). Consideraram-se três tamanhos de rebanho (50, 
100 e 200 vacas em lactação) e três taxas médias cobradas pelos núcleos para a realização do CL ( $\mathrm{R} \$ 1,50 /$ vaca até 50 vacas; $\mathrm{R} \$ 1,40 /$ vaca de 51 a 100 vacas e $R \$ 1,30 /$ vaca para mais de 100 vacas controladas).

Os preços das análises qualitativas do leite foram os cobrados pelo laboratório de análises da clínica do leite da ESALQ-USP (Dagher, 2001), de acordo com o número de vacas controladas: a) $50-100$ vacas, $\mathrm{R} \$ 0,43$ para CCS e $\mathrm{R} \$ 0,57$ para composição (gordura e proteína); b) acima de 100 vacas, $\mathrm{R} \$ 0,40$ para CCS e $\mathrm{R} \$ 0,50$ para composição (gordura e proteína).

Os valores de diária, quilometragem e taxas individuais de controle leiteiro foram levantados em dois núcleos de controle leiteiro do Estado de São Paulo. O valor da diária foi de $\mathrm{R} \$ 45,00$ (25\% salário mínimo), o valor da quilometragem (R\$0,60) correspondeu a $35 \%$ do preço de um litro de gasolina $(\mathrm{R} \$ 1,70)$. A cotação do dólar comercial na ocasião em que os cálculos foram efetuados correspondeu a $\mathrm{R} \$ 2,50$, enquanto que a média dos últimos 12 meses foi de $\mathrm{R} \$ 2,07$ (Anuário..., 2000, 2001). Foi estabelecida distância média percorrida de $150 \mathrm{~km}$ por controle para cada um dos esquemas de controle leiteiro.

A partir desses valores definiram-se as planilhas de cálculo com o auxílio do programa Microsoft Excel 5.0, para a obtenção dos custos mensais parciais (sem levar em conta a quilometragem) e total para cada alternativa estudada. Os esquemas alternativos foram: esquema 1- freqüência mensal (situação básica), com pesagens de todas as ordenhas; esquema 2- freqüência mensal com pesagens alternadas, ordenha da manhã ou ordenha da tarde; esquema 3- freqüência bimensal, com pesagens de todas as ordenhas; esquema 4- freqüência bimensal com pesagens alternadas, ordenha da manhã ou ordenha da tarde; esquema 5- supervisão trimestral, com uso dos controles intermediários realizados pela fazenda e análise qualitativa mensal do leite; esquema 6- supervisão trimestral, com uso dos controles intermediários realizados pela fazenda e análise qualitativa trimestral do leite.

Para cada um dos esquemas definiram-se, ainda, quatro possibilidades de análise qualitativa do leite: a- ausência de análise, b- análise da composição do leite (teores de gordura e proteína), c- CCS e d- análise de composição e de CCS.

Supondo-se a produção média de $25 \mathrm{~kg}$ leite/vaca/dia, foram calculados, para cada caso, o percentual que o custo total com o controle leiteiro representaria em relação à receita bruta mensal do leite (CL/RB), tomando-se por base o preço do leite $\mathrm{B}$ de $\mathrm{R} \$ 0,39$ (média dos últimos 12 meses; Anuário..., 2000, 2001), e em relação à receita líquida mensal (CL/RL), com base no valor de margem líquida média de $\mathrm{R} \$ 0,04$. Foram avaliados os efeitos da variação de alguns parâmetros definidos na situação básica sobre esses percentuais, como se segue: a- aumento e diminuição em $20 \%$ no nível de produção média diária sobre $\mathrm{CL} / \mathrm{RB}$ e $\mathrm{CL} / \mathrm{RL}$, b- aumento e diminuição em $10 \%$ nos valores do preço do leite sobre $\mathrm{CL} / \mathrm{RL}$, e c- aumento e diminuição em $50 \%$ do valor da margem líquida sobre $\mathrm{CL} / \mathrm{RL}$, de modo a obter margens de $\mathrm{R} \$ 0,02$ e $\mathrm{R} \$ 0,06$, valores escolhidos por representarem exemplos de margens possíveis de serem obtidas na atual conjuntura da pecuária leiteira paulista (comunicação pessoal ${ }^{1}$ ).

\section{RESULTADOS E DISCUSSÃO}

Na Tab. 1 são apresentados, para cada esquema de controle leiteiro, os custos mensais parciais (sem levar em conta a quilometragem) e total por rebanho e por vaca, supondo-se distância média percorrida de $150 \mathrm{~km}$ e número médio de vacas em lactação por rebanho de 50, 100 e 200 vacas.

Em relação à freqüência de controle, o esquema 1 foi o que apresentou maior custo mensal, enquanto que os esquemas 4, 5 e 6 apresentaram os menores custos mensais. Eles foram altamente influenciados pelo número de vacas, isto é, quanto maior o número, menor o custo por vaca. Os esquemas 2 e 3 foram equivalentes em relação aos custos com diárias e quilometragem.

Quanto à operacionalidade, o esquema 4 apresentou a vantagem de permitir ao controlador realizar mais controles, isto é, ser responsável por maior número de rebanhos. Os esquemas 5 e 6 foram mais fáceis de serem implementados, isto é, bastou ao fazendeiro realizar o próprio controle e enviar as

\footnotetext{
${ }^{1}$ Nogueira, J.R. (2001)
} 
informações mensais para o núcleo responsável. Em termos de estrutura de serviço de controle leiteiro, os custos com diária e quilometragem para a fazenda seriam reduzidos em $50 \%$ nos casos dos esquemas 2 e 3 , em dois terços nos esquemas 5 e 6 e em três quartos no esquema 4 , refletindo nos custos por vaca.

Tabela 1. Custos mensais de controle leiteiro (R\$), de acordo com o esquema de controle leiteiro, o número de vacas em lactação e a análise qualitativa do leite ${ }^{\#}$

\begin{tabular}{|c|c|c|c|}
\hline \multirow{2}{*}{ Esquema/análise qualitativa } & \multicolumn{3}{|c|}{ Vacas em lactação } \\
\hline & 50 & 100 & 200 \\
\hline Esquema 1 & \multicolumn{3}{|c|}{$\operatorname{Valor}(R \$)$} \\
\hline Nenhuma análise & $210,00(120,00) 4,20$ & $275,00(185,00) 2,75$ & $305,00(305,00) 1,98$ \\
\hline Composição & $238,50(148,50) 4,77$ & $332,00(242,00) 3,32$ & $495,00(405,00) 2,48$ \\
\hline $\mathrm{CCS}$ & $231,50(141,50) 4,63$ & $318,00(228,00) 3,18$ & $475,00(385,00) 2,38$ \\
\hline Composição + CCS & $260,00(170,00) 5,20$ & $375,00(285,00) 3,75$ & $575,00(485,00) 2,88$ \\
\hline Esquema 2 & \multicolumn{3}{|c|}{$\operatorname{Valor}(R \$)$} \\
\hline Nenhuma análise & $187,50(97,50) 3,75$ & $252,50(162,50) 2,53$ & $372,50(282,50) 1,86$ \\
\hline Composição & $216,00(126,00) 4,32$ & $309,50(219,50) 3,10$ & $472,50(382,50) 2,36$ \\
\hline $\mathrm{CCS}$ & $209,00(119,00) 4,18$ & $295,50(205,50) 2,96$ & $452,50(362,50) 2,26$ \\
\hline Composição + CCS & $237,50(147,50) 4,75$ & $352,50(262,50) 3,53$ & $552,50(462,50) 2,76$ \\
\hline Esquema 3 & \multicolumn{3}{|c|}{ Valor $(R \$)$} \\
\hline Nenhuma análise & $187,50(97,50) 3,75$ & $252,50(162,50) 2,53$ & $372,50(282,50) 1,86$ \\
\hline Composição & $201,50(111,50) 4,03$ & $280,50(190,50) 2,81$ & $422,50(332,50) 2,11$ \\
\hline $\mathrm{CCS}$ & $198,50(108,50) 3,97$ & $274,50(184,50) 2,75$ & $412,50(322,50) 2,06$ \\
\hline Composição + CCS & $212,50(122,50) 4,25$ & $302,50(212,50) 3,03$ & $462,50(372,50) 2,31$ \\
\hline Esquema 4 & \multicolumn{3}{|c|}{$\operatorname{Valor}(R \$)$} \\
\hline Nenhuma análise & $176,25(86,25) 3,53$ & $241,25(151,25) 2,41$ & $361,25(271,25) 1,81$ \\
\hline Composição & $190,25(100,25) 3,81$ & $269,25(179,25) 2,69$ & $411,25(321,25) 2,06$ \\
\hline $\mathrm{CCS}$ & $187,25(97,25) 3,75$ & $263,25(173,25) 2,63$ & $401,25(311,25) 2,01$ \\
\hline Composição + CCS & $201,25(11,25) 4,03$ & $291,25(201,25) 2,91$ & $451,25(261,25) 2,26$ \\
\hline Esquema 5 & \multicolumn{3}{|c|}{ Valor $(R \$)$} \\
\hline Nenhuma análise & $180,00(90,00) 3,60$ & $245,00(155,00) 2,45$ & $365,00(275,00) 1,83$ \\
\hline Composição & $208,50(118,50) 4,17$ & $302,00(212,00) 3,02$ & $465,00(375,00) 2,33$ \\
\hline $\mathrm{CCS}$ & $201,50(111,50) 4,03$ & $288,00(198,00) 2,88$ & $445,00(355,00) 2,23$ \\
\hline Composição + CCS & $230,00(140,00) 4,60$ & $345,00(255,00) 3,45$ & $545,00(455,00) 2,73$ \\
\hline Esquema 6 & \multicolumn{3}{|c|}{ Valor $(R \$)$} \\
\hline Nenhuma análise & $180,00(90,00) 3,60$ & $245,00(155,00) 2,45$ & $365,00(275,00) 1,83$ \\
\hline Composição & $190,00(100,00) 3,80$ & $265,00(175,00) 2,65$ & $399,00(309,00) 2,00$ \\
\hline $\mathrm{CCS}$ & $187,50(97,50) 3,75$ & $260,00(170,00) 2,60$ & $393,00(303,00) 1,97$ \\
\hline Composição + CCS & $197,50(107,50) 3,95$ & $280,00(190,00) 2,80$ & $425,00(335,00) 2,13$ \\
\hline
\end{tabular}

Esquema 1: Freqüência mensal (situação básica), com pesagens de todas as ordenhas.

Esquema 2: Freqüência mensal com pesagens alternadas, ordenha da manhã / ordenha da tarde.

Esquema 3: Freqüência bimensal, com pesagens de todas as ordenhas.

Esquema 4: Freqüência bimensal com pesagens alternadas, ordenha da manhã / ordenha da tarde.

Esquema 5: Supervisão trimestral, controles intermediários realizados pela fazenda e análise mensal do leite.

Esquema 6: Supervisão trimestral, controles intermediários realizados pela fazenda e análise trimestral do leite.

\#Os valores em itálico correspondem ao custo total por rebanho levando-se em conta a distância média percorrida de $150 \mathrm{~km}$; os valores entre parênteses correspondem ao custo sem levar em conta o valor da quilometragem; os valores em negrito referem-se aos custos por vaca.

Considerando os custos com as análises de composição do leite e CCS, os esquemas 4 e 6 foram os mais vantajosos por apresentarem intervalos maiores entre as análises. O esquema 3 foi vantajoso em relação ao esquema 1 por resultar na redução em 50\% no custo das análises. $\mathrm{O}$ esquema 4 prevê a realização bimensal de análises de leite a partir de amostras coletadas alternadamente pela manhã e à tarde. No entanto, sabe-se que há um efeito do número 
e do intervalo de ordenhas sobre a composição e a CCS. Para a adoção deste esquema é necessária a padronização da ordenha em que a amostra é coletada. Em casos de necessidade de análises mensais (avaliação da CCS em programas de controle de mastite, por exemplo), talvez o esquema 5 seja mais interessante, embora dependa da coleta de amostras pelo fazendeiro nos meses intermediários aos do controle de supervisão. Todavia, dada a similaridade de custos nos esquemas 3, 4 e 6 , poder-se-ia escolher o que melhor se ajustasse às necessidades do produtor.

Em propriedades com casos sistemáticos de CCS acima dos padrões, a realização de análises individuais periódicas de CCS para o desenvolvimento de programas de controle de mastite clínica e sub-clínica poderia ser de grande benefício. Quando existe o pagamento diferenciado para qualidade do leite, além do controle da CCS, pode ser economicamente interessante modificar a composição do leite das vacas do rebanho. Isto pode ser feito mediante modificações na dieta, em especial para mudanças no teor de gordura (Suton e Morant, 1989) e por meio de melhoramento genético (Gibson, 1987; Dürr e Rorato, 2000). Neste caso, a realização periódica de análises individuais de composição é indicada. Em qualquer situação, a decisão de realizar ou não análises qualitativas e a sua freqüência deve ser tomada com base na estimativa dos custos adicionais e do retorno esperado.

A Tab. 2 apresenta, para os esquemas 1,3 e 6 , o percentual representado pelo custo mensal com o $\mathrm{CL}$ em relação à receita bruta mensal proveniente da venda do leite $(\mathrm{CL} / \mathrm{RB})$ e em relação à receita líquida mensal $(\mathrm{CL} / \mathrm{RL})$ com base no valor de margem líquida de $\mathrm{R} \$ 0,04 / 1$, de acordo com o tamanho do rebanho e a análise qualitativa do leite. Em ambos os casos considerou-se um nível de produção de $25 \mathrm{~kg}$ de leite/vaca/dia.

Tabela 2. Custo mensal (\%) do controle leiteiro em relação à receita bruta mensal e à receita líquida, de acordo com o número de vacas e a análise qualitativa do leite, para os esquemas 1, 3 e 6 e supondo-se a produção de leite de $25 \mathrm{~kg} / \mathrm{vaca} /$ dia

\begin{tabular}{lccc}
\hline Esquema/análise qualitativa & \multicolumn{3}{c}{ Vacas em lactação } \\
\cline { 2 - 4 } Esquema 1 & 50 & 100 & 200 \\
$\quad$ Nenhuma análise & $1,41(13,8)$ & $0,96(9,34)$ & $0,73(7,13)$ \\
Composição & $1,60(15,6)$ & $1,15(11,21)$ & $0,92(9,00)$ \\
CCS & $1,55(15,1)$ & $1,10(10,75)$ & $0,87(8,54)$ \\
Composição + CCS & $1,75(17,04)$ & $1,30(12,62)$ & $1,06(10,40)$ \\
Esquema 3 & & & $0,69(6,76)$ \\
Nenhuma análise & $1,26(12,30)$ & $0,88(8,60)$ & $0,78(7,69)$ \\
Composição & $1,35(13,21)$ & $0,97(9,52)$ & $0,76(7,49)$ \\
CCS & $1,33(13,01)$ & $0,95(9,32)$ & $0,86(8,40)$ \\
Composição + CCS & $1,42(13,93)$ & $1,05(10,24)$ & $0,68(6,63)$ \\
Esquema 6 & & & $0,74(7,30)$ \\
Nenhuma análise & $1,21(11,80)$ & $0,85(8,36)$ & $0,73(7,13)$ \\
Composição & $1,28(12,45)$ & $0,92(9,01)$ & $0,80(7,79)$ \\
CCS & $1,26(12,30)$ & $0,90(8,85)$ & $0,97(9,5)$ \\
Composição + CCS & $1,32(12,95)$ & &
\end{tabular}

Esquema 1: Freqüência mensal (situação básica), com pesagens de todas as ordenhas.

Esquema 3: Freqüência bimensal, com pesagens de todas as ordenhas.

Esquema 6: Supervisão trimestral, controles intermediários realizados pela fazenda e análise trimestral do leite.

Os valores fora do parênteses correspondem ao custo do controle leiteiro em relação à receita bruta com a venda do leite $(\mathrm{CL} / \mathrm{RB}) \mathrm{e}$

os entre parênteses à receita líquida estimada a partir de uma margem líquida de R $\$ 0,04 / 1$. CCS= contagem de células somáticas.

O custo mensal do CL representou de $0,68 \%$ a $1,75 \%$ sobre a receita bruta e de $6,63 \%$ a $17,04 \%$ sobre a receita líquida. Os valores obtidos para o esquema 6 foram menores, indicando ser economicamente o mais favorável. CL/RB e $\mathrm{CL} / \mathrm{RL}$ foram influenciados pelo número de 
animais no rebanho, independentemente da realização de análises qualitativas, isto é, quanto maior o número de vacas, menor o valor obtido. De maneira geral, os custos individuais para rebanhos com 200 vacas em lactação corresponderam a $50-60 \%$ dos calculados para rebanhos com 50 vacas em lactação. As diferenças entre esquemas foram acentuadas para rebanhos menores, mostrando o impacto do custo do CL para pequenos produtores. Por exemplo, a vantagem dos esquemas 3 e 6 em relação ao esquema 1, expressa em termos de redução nos valores de CL/RL (sem análise qualitativa do leite) foi, respectivamente, $11 \%$ e $15 \%, 8$ e $10 \%$ e $5 \%$ e $7 \%$, para rebanhos de 50,100 e 200 vacas.

O efeito do número de vacas no rebanho sobre o impacto dos custos com CL pode ser evidenciado tomando-se por exemplo o esquema 6 (sem análise qualitativa do leite). Aumentando o número de vacas de 50 para 200 , haveria redução em $44 \%$ no valor de CL/RB e $29 \%$ no valor de CL/RL.

Dentro de cada esquema, o impacto do tipo de análise qualitativa foi menor no esquema $6 \mathrm{e}$ em rebanhos maiores devido à redução de preços individuais das análises. Nota-se que, para o mesmo número de vacas, os valores de CL/RB e CL/RL para o esquema 6 , com análises de composição e CCS, foram equivalentes ou muito próximos aos valores obtidos para o esquema 3 , somente com análise de CCS ou composição e aos obtidos para o esquema 1 , sem análise qualitativa.

$\mathrm{Na}$ Tab. 3 são mostrados os efeitos da variação no preço do leite e no nível de produção da vaca sobre CL/RB.

Tabela 3. Custo do controle leiteiro (\%) em relação à receita bruta após mudanças no preço do leite (+ $10 \%$ e $-10 \%)$ e no nível de produção da vaca $(+20 \%$ e $-20 \%)$, na ausência de análises qualitativas, para os esquemas 1,3 e 6 , de acordo com o número de vacas em lactação

\begin{tabular}{|c|c|c|c|c|c|c|}
\hline \multirow{2}{*}{ Esquema/No. vacas } & \multicolumn{3}{|c|}{ Preço do leite $^{1}$} & \multicolumn{3}{|c|}{ Produção diária $^{1}$} \\
\hline & $-10 \%$ & $\mathrm{R} \$ 0,39$ & $+10 \%$ & $-20 \%$ & $25 \mathrm{~kg}$ & $+20 \%$ \\
\hline \multicolumn{7}{|l|}{ Esquema 1} \\
\hline 50 vacas & 1,57 & 1,41 & 1,28 & 1,76 & 1,41 & 1,18 \\
\hline 100 vacas & 1,07 & 0,96 & 0,87 & 1,20 & 0,96 & 0,80 \\
\hline 200 vacas & 0,81 & 0,73 & 0,66 & 0,91 & 0,73 & 0,60 \\
\hline \multicolumn{7}{|l|}{ Esquema 3} \\
\hline 50 vacas & 1,41 & 1,26 & 1,14 & 1,58 & 1,26 & 1,05 \\
\hline 100 vacas & 0,98 & 0,88 & 0,80 & 1,10 & 0,88 & 0,73 \\
\hline 00 vacas & 0,77 & 0,69 & 0,63 & 0,87 & 0,70 & 0,58 \\
\hline \multicolumn{7}{|l|}{ Esquema 6} \\
\hline 50 vacas & 1,35 & 1,21 & 1,10 & 1,51 & 1,21 & 1,00 \\
\hline 100 vacas & 0,96 & 0,86 & 0,78 & 1,07 & 0,86 & 0,71 \\
\hline 200 vacas & 0,76 & 0,68 & 0,62 & 0,85 & 0,68 & 0,57 \\
\hline
\end{tabular}

Esquema 1: Freqüência mensal (situação básica), com pesagens de todas as ordenhas.

Esquema 3: Freqüência bimensal, com pesagens de todas as ordenhas.

Esquema 6: Supervisão trimestral, controles intermediários realizados pela fazenda e análise trimestral do leite.

${ }^{1}$ Redução ou aumento em relação ao preço base de $\mathrm{R} \$ 0,39$; redução ou aumento em relação à produção base de $25 \mathrm{~kg}$.

O incremento da receita bruta decorrente dos aumentos no preço do leite e no nível de produção resultou em diminuição do CL/RB para os três esquemas. Vale salientar que o impacto da redução no preço do leite ou no nível de produção sobre CL/RB foi menor no esquema 6 e em rebanhos maiores. Todavia, os custos adicionais necessários para manter vacas de maior produção devem ser considerados para avaliar o custo-benefício dos diferentes esquemas de CL na receita líquida da fazenda. Para melhor visualização dessa questão, variouse o valor da margem líquida em $50 \%$ para mais ou para menos ( $\mathrm{R} \$ 0,02$ e $\mathrm{R} \$ 0,06)$, escolhidos por representarem exemplos de valores passíveis de serem obtidos na atual conjuntura da pecuária leiteira paulista (Tab. 4). Rebanhos mais eficientes tendem a apresentar margem maior e, nesse caso, o custo com CL terá menor impacto na receita líquida da fazenda. O CL poderia 
concorrer para aumentar a eficiência de produção pela possibilidade de controlar a quantidade de alimento fornecida aos animais e pela otimização do descarte de vacas de baixa produção, melhorando a relação custo $\mathrm{CL} x$ margem líquida.

Tabela 4. Custo do controle leiteiro (\%) em relação à receita líquida após mudanças na margem líquida $(+50 \%$ e $-50 \%)$ e no nível de produção da vaca $(+20 \%$ e $-20 \%)$, na ausência de análises qualitativas, para os esquemas 1,3 e 6 , de acordo com o número de vacas em lactação

\begin{tabular}{|c|c|c|c|c|c|c|}
\hline \multirow{2}{*}{ Esquema $/ \mathrm{N}^{\circ}$. vacas } & \multicolumn{3}{|c|}{ Margem líquida $^{1}$} & \multicolumn{3}{|c|}{ Produção diária $^{1}$} \\
\hline & $-50 \%$ & $\mathrm{R} \$ 0,04$ & $+50 \%$ & $-20 \%$ & $25 \mathrm{~kg}$ & $+20 \%$ \\
\hline \multicolumn{7}{|l|}{ Esquema 1} \\
\hline 50 vacas & 27,54 & 13,78 & 9,18 & 17,21 & 13,78 & 11,48 \\
\hline 100 vacas & 18,69 & 9,35 & 6,23 & 11,69 & 9,35 & 7,79 \\
\hline 200 vacas & 14,26 & 7,13 & 4,75 & 8,92 & 7,13 & 5,95 \\
\hline \multicolumn{7}{|l|}{ Esquema 3} \\
\hline 50 vacas & 24,60 & 12,30 & 8,20 & 15,37 & 12,30 & 10,25 \\
\hline 100 vacas & 17,21 & 8,60 & 5,73 & 10,75 & 8,60 & 7,17 \\
\hline 200 vacas & 13,52 & 6,76 & 4,50 & 8,45 & 6,76 & 5,63 \\
\hline \multicolumn{7}{|l|}{ Esquema 6} \\
\hline 50 vacas & 23,60 & 11,80 & 7,87 & 14,75 & 11,80 & 9,84 \\
\hline 100 vacas & 16,72 & 8,36 & 5,58 & 10,45 & 8,36 & 6,97 \\
\hline 200 vacas & 13,28 & 6,64 & 4,42 & 8,30 & 6,64 & 5,54 \\
\hline
\end{tabular}

Esquema 1: Frequência mensal (situação básica), com pesagens de todas as ordenhas.

Esquema 3: Frequência bimensal, com pesagens de todas as ordenhas.

Esquema 6: Supervisão trimestral, controles intermediários realizados pela fazenda e análise trimestral do leite.

${ }^{1}$ Redução ou aumento em relação à margem líquida base de $\mathrm{R} \$ 0,04$; redução ou aumento em relação à produção base de $25 \mathrm{~kg}$.

Como subsídio para a constituição de novos núcleos de controle leiteiro, na Tab. 5 é apresentado um exemplo de estrutura de um núcleo de CL com os respectivos custos mensais, no qual o valor total mensal foi de $\mathrm{R} \$ 3.000,00$. Supondo-se um núcleo com 100 associados e número médio de vacas em lactação por rebanho de 50, no total seriam 5.000 vacas controladas. Dividindo-se $\mathrm{R} \$ 3.000,00$ por 5.000 vacas, seria necessário cobrar uma taxa mensal de $\mathrm{R} \$ 0,60 / \mathrm{vaca} / \mathrm{mês}$. Atualmente, este valor gira em torno de $\mathrm{R} \$ 1,50$, insuficiente para a número atual de vacas controladas.

Tabela 5. Custo mensal para manutenção de um núcleo regional de controle leiteiro, supondo-se 100 rebanhos e média de 50 vacas em lactação por rebanho

\begin{tabular}{lc}
\hline Item de despesa & Custo \\
\hline Aluguel + despesas & 750,00 \\
Salário e encargos & $1.500,00$ \\
Manutenção computadores & 180,00 \\
Material informática/escritório & 250,00 \\
Correio & 200,00 \\
Outras despesas & 120,00 \\
Total & $3.000,00$ \\
\hline
\end{tabular}

Arq. Bras. Med. Vet. Zootec., v.57, n.1, p.85-92, 2005
O aumento do número de rebanhos controlados resultaria na diminuição das taxas cobradas pelos núcleos para o processamento dos dados, emissão de relatórios e certificados. Como sugerem Madalena (1998) e Wilmink (1998), os dados colhidos no processo de CL podem viabilizar a confecção de relatórios adicionais de manejo que podem auxiliar os fazendeiros a melhorar sua eficiência econômica, reduzindo, assim, o impacto dos seus custos de realização.

Todavia, um dos fatores preponderantes para aumentar o número de rebanhos controlados é o esclarecimento dos produtores e/ou responsáveis pelo manejo dos rebanhos a respeito da importância do CL e das ações necessárias para sua implementação e execução. Segundo Wilmink (1998), as organizações de CL deverão considerar os fazendeiros cada vez mais como clientes e aborda-los cada vez menos com intenção de fiscais. Em muitos países existe uma tendência em reduzir o apoio econômico do estado às organizações responsáveis pelo CL. Para sobreviver, elas terão de estabelecer parcerias com outras organizações envolvidas, de alguma maneira, com o melhoramento genético de gado leiteiro. No caso do Brasil, a integração 
adequada entre fazendeiros, núcleos de controle leiteiro, laboratórios de análise de qualidade, instituições de pesquisa e outros beneficiários potenciais das informações geradas (centrais de inseminação, orgãos das secretarias de agricultura, cooperativas/indústrias de laticínios, associações de raças e/ou de produtores etc.), poderia proporcionar, além de redução dos custos, a otimização do uso das informações e o desenvolvimento de programas de melhoramento genético e de controle de doenças, em especial da mastite.

\section{CONCLUSÕES}

Com base nos resultados foi possível concluir que: 1- é possível reduzir os custos de controle leiteiro mediante a adoção de esquemas mais flexíveis, com maior intervalo entre controle e/ou menor número de ordenhas controladas, ou ainda com o aproveitamento do controle leiteiro intermediário realizado pelo próprio fazendeiro; 2- quanto maior o tamanho do rebanho, menor é o impacto da realização de análises qualitativas sobre o custo do CL; 3- aumentos no preço do leite, no nível de produção e na margem líquida resultam em relações favoráveis entre o custo do $\mathrm{CL}$ e as receitas bruta e líquida da fazenda.

\section{REFERÊNCIAS BIBLIOGRÁFICAS}

ANUÁRIO de Informações Estatísticas da Agricultura, 1999/2000. Disponível em: $<$ www.iea.sp.gov.br/out/ibcoiea.htm>. Acessado em 25/06/2004.
DAGHER, L. Clínica do leite. Piracicaba: ESALQ, USP (material de divulgação), 2001. $59 \mathrm{p}$.

DÜRR, J.W.; RORATO, P.R.N. Seleção para qualidade e composição do leite. Palavras e atitudes. In: SIMPÓSIO NACIONAL DA SOCIEDADE BRASILEIRA DE MELHORAMENTO ANIMAL, 3., 2000, Belo Horizonte-MG. Anais... SBMA, 2000. P.237247.

GIBSON, J.P. The options and prospects for genetically altering milk composition in dairy cattle. Anim. Breed. Abstr., v.55, p.231-243, 1987.

MADALENA, F.E. Experiences with performance recording of dairy cattle in Brazil. In: WORKSHOP ON ANIMAL RECORDING FOR SMALL HOLDERS IN RURAL AREAS IN DEVELOPING COUNTRIES. Proc. ICAR/FAO. Annand, India, 1998.

MADALENA, F.E. Consequências econômicas da seleção para gordura e proteína do leite. Rev. Bras. Zootec., v.29, p.678-684, 2000a.

MADALENA, F.E. Valores econômicos para seleção de gordura e proteína do leite. Rev. Bras. Zootec., v.29, p.685-691, 2000b.

SUTTON, J.D.; MORANT, S.V. A review of the potential of nutrition to modify milk fat and protein. Livest. Prod. Sci., v.23, p.219-237, 1989.

WILMINK, J.B.M. State of the art and trends in animal recording. In: SIMPÓSIO NACIONAL DA SOCIEDADE BRASILEIRA DE MELHORAMENTO ANIMAL, 2., 1998, Uberaba, MG. Anais... SBMA, 1998. P.1-9. 